\title{
MASTER
}

\section{Hot-Ion Distribution Function in ORMAK, the Oak Ridge Tokamak}

\author{
R. V. Neidigh \\ D. J. Sigmar
}




\section{DISCLAIMER}

This report was prepared as an account of work sponsored by an agency of the United States Government. Neither the United States Government nor any agency Thereof, nor any of their employees, makes any warranty, express or implied, or assumes any legal liability or responsibility for the accuracy, completeness, or usefulness of any information, apparatus, product, or process disclosed, or represents that its use would not infringe privately owned rights. Reference herein to any specific commercial product, process, or service by trade name, trademark, manufacturer, or otherwise does not necessarily constitute or imply its endorsement, recommendation, or favoring by the United States Government or any agency thereof. The views and opinions of authors expressed herein do not necessarily state or reflect those of the United States Government or any agency thereof. 


\section{DISCLAIMER}

Portions of this document may be illegible in electronic image products. Images are produced from the best available original document. 
Printed in the United States of America. Available from National Technical Information Service

U.S. Department of Commerce

5285 Port Royal Road, Springfield, Virginia 22161

Price: Printed Copy $\$ 4.50$; Microfiche $\$ 3.00$

This report was prepared as an account of work sponsored by an agency of the United States Government. Neither the United States Government nor any agency thereof, nor any of their employees, contractors, subcontractors, or their employees, makes any warranty, express or implied, nor assumes any legal liability or responsibility for any third party's use or the results of such use of any information, apparatus, product or process disclosed in this report, nor represents that its use by such third party would not intringe privately owned rights. 
Contract No. W-7405-eng-26

FUSION ENERGY DIVISION

HOT-ION DISTRIBUTION FUNCTION IN ORMAK,

THE OAK RIDGE TOKAMAK

R. V. Neidigh and D. J. Sigmar

Date Published - March 1978

This report was prepared as an account of work sponsored by the United States Govermment. Neither the United States nor the United States Department of Energy, nor any of their employees, nor any of their contractors, subcontractors, or their employees, makes any watranty, exprece or implied, or assumes any legal liability or responsibility for the accuracy, completeness or usefulness of any information, apparatus, product or
process disclosed, or represents that its use would not infringe privately owned rights.

1

Prepared by the OAK RIDGE NATIONAL LABORATORY Oak Ridge, Tennessee 37830 operated by UNION CARBIDE CORPORATION for the DEPARTMENT OF ENERGY 
THIS PAGE

\section{WAS INTENTIONALLY \\ LEFT BLANK}




\section{CONTENTS}

ABSTRACT . . . . . . . . . . . . . . . . . . . . . 1

1. INTRODUCTION . . . . . . . . . . . . . . . . . 1

2. DATA COLLECTION SYSTEM . . . . . . . . . . . . . . . 3

3. OUTLINE OF THEORY . . . . . . . . . . . . . . . . . . 4

4. LINE PROFILE UNFOLDING TECHNIQUE . . . . . . . . . . . . . . 9

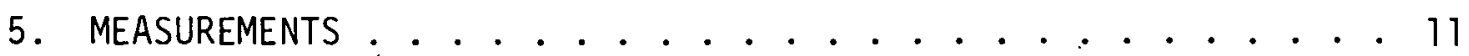

6. CONCLUSIONS ....................... 12

ACKNOWLEDGMENTS . . . . . . . . . . . . . . . . . . 13

REFERENCES ........................... . . 14

FIGURE CAPTIONS . . . . . . . . . . . . . . . . . . 15 
HOT-ION DISTRIBUTION FUNCTION IN ORMAK, THE OAK RIDGE TOKAMAK

R. V. Neidigh and D. J. Sigmar

Abstract--A distortion of the Maxwellian ion-energy distribution function in tokamak-produced plasmas may be revealed in the spectral-line radiation. We report experimental evidence that (1) a change in the value of $Z$ eff, (2) delayed gas injection, (3) neutral beam injection, and (4) liner cleaning procedures can alter the profile of the Balmer- $\alpha(6563 \stackrel{\circ}{A})$ line of hydrogen. The distortion is analyzed in terms of an effective toroidal-drift velocity, ion-temperature relation.

\section{INTRODUCTION}

It has been observed that tokamak plasmas execute poloidal rotation early and late, and toroidal rotation during the constant current portion of the ohmic heating cycle. Early theories of poloidal rotation were given by STRINGER (1970) and toroidal rotation by ROSENBLUTH et a 1. (1971). The theories were later reviewed by HINTON and HAZELTINE (1976). Recently, HIRSHMAN (1977) has determined the poloidal and toroidal ion flow velocities in all collisionality regimes from a fluid theory point of view. The observed toroidal rotational velocity of the plasma was theoretically shown by SIGMAR et al. (1974) to be related to the existence of trapped particles. We reported, at that time, an experimental observation in the ORMAK-produced plasma of an apparent linear relation between ion temperature and toroidal-drift velocity. A more recent observation (BELL, 1977) of toroidal rotation is that of a Doppler shift in the $0 \mathrm{~V}(2781 \AA$ A) radiation from LT-3, operating in the plateau and collisional regimes. In 1976 we reexamined the Balmer- $\alpha(6563 \mathrm{~A})$ spectral line profile of many ORMAK shots 
with a multichannel, time-integrating detection and collection system instead of the single channel scanning system previously used. We substantiated that there is indeed a systematic distortion of the Balmer- $\alpha$ line profile of hydrogen and that it appears to be related to ion temperature as we reported in 1974. A discussion of the effective toroidal-drift velocity $\left(v_{\| i}\right)$, ion-temperature $\left(T_{j}\right)$ relation, and the plasma parameters which affect $d v_{\| j} / d T_{i}$ will be presented in this paper. Poloidal rotation will not be cunsidered. This paper will also describe the components of the improved detection system, describe the line-profile unfolding technique, and suggest a possible spatial distribution of the toroidal-drift velocity.

Our objective in reporting these observations is fourfold:

(1) Although the source of $H_{\alpha}$ radiation is predominantly the cold edge of the plasma, the intensity of radiation in the wings of the line profile is sufficiently above the noise level to permit $d v_{\| j} / d T_{j}$ analysis in the energy range up to ten times thermal. This is a worthwhile complement to the ion-temperature determined from charge-exchange analysis of the high energy tail of the distribution function.

(2) It is conjectured that the effective toroidal-drift velocity, ion-temperature relation may become a shot-to-shot plasma quality indicator since $d v_{\| i} / d T_{i}$ appears to be sensitive to injected hydrogen gas (gas puffing) and neutral injection which, in turn, alters $Z_{\text {eff }}$.

(3) The expected increase in toroidal-drift velocity due to tangential neutral injection, as indicated by the charge-exchange analyzers as well as by the $H_{\alpha}$ radiation, was found to be anomalously small. The $\mathrm{dv}_{\| i} / \mathrm{dT}_{i}$ relation may quantify the effects of ripple viscosity as described by TSANG and FRIEMAN (1976). More recently TSANG (1977) has shown that a $1 \%$ drift-wave 
turbulence level suffices to provide enough ion viscosity to anomalously damp the toroidal rotation produced by parallel neutral-particle injection. Anomalous damping may also be caused by microturbulence first suspected by RUDAKOV and ZAVOISKY (1967) and later, with more detail by CALLEN et al. (1973).

(4) A spatial distribution of the toroidal-drift velocity is found by combining these results, $v_{\| j}\left(T_{j}\right)$, with the ion-temperature distribution, $T_{j}(r)$, from the charge-exchange analyzer.

\section{DATA COLLECTION SYSTEM}

Our method of observation incorporated a 3/4-m Czerny-Turner spectrometer with the associated optics for the selection of a band of radiation of 2125 A width. Detection, timing, integration, and digitization of the radiation was accomplished by an optical multichannel analyzer (OMA) system. A dedicated computer was used for data storage and analysis. The apparatus is schematized in Fig. 1. Simply by positioning the entrance slit of the spectrometer, it was possible to collect radiation using either an upstream or a downstream view with respect to the direction of conventional current in the ohmically heated plasma. Spatial resolution is not directly obtained by this technique but may be estimated indirectly through an ion temperature distribution, as will be shown. Radiation was collected along a path lying tangent to the inside edge of the ORMAK liner in the midplane. A geometrical analysis shows that for the ORMAK dimensions $(R \approx 4 r)$, the average angle between the path of radiation collection and the toroidal direction of flow is about $45^{\circ}$. We have corrected for this by increasing all velocities calculated from the measured Doppler shift by a factor of 1.4. The reciprocal dispersion of the system was of the order of $1 / 4 \AA$ per channel of the vidicon detector, and 
therefore the conversion of channel number to wavelength could be in error by as much as $1 / 8 \AA$ corresponding to a possible factor-of-two error for the lowest values of drift velocity measured or as much as $10 \mathrm{eV}$ at thermal ion temperatures.

\section{OUTLINE OF THEORY}

To understand the observed Doppler shifts (or more precisely, the asymmetric distortions of the $H_{\alpha}$ line bearing the signature of the proton velocity distribution), it is useful to first review the fluid picture of plasma flows (HIRSHMAN 1977). During the constant. current phase of the tokamak discharge, one expects to observe a steady-state ion flow velocity driven by the pressure gradient and the radial electric field. Whereas in a current free cylinder these flows would simply occur in the poloidal direction, the helical field line structure and the toroidal geometry (producing trapped particle effects) lead to surprising deviations from the classical picture, depending also on the collisionality parameter $v_{\star}$. Beyond that, to fully understand the observed distortions in the superthermal wings of the $H_{\alpha}$ line it will be necessary to briefly review the kinetic theory of the distribution furiction of the ion (guiding center) velocities given before (SIGMAR, CLARKE 1974 ).

\subsection{Fluid Description}

HIRSHMAN (1977) has shown that the poloidal, toroidal, and parallel fluw. velocities of the ions are given by

where

$$
\begin{aligned}
& u_{P_{i}}=u_{i}(\psi /) B_{\mu} \\
& u_{T i}=\left\langle v_{1 i} B\right\rangle / B_{T}+u_{i}(\psi) B_{T} \\
& u_{\| i}=v_{1 i}+u_{i}(\psi) B
\end{aligned}
$$

$$
u_{j}(\psi) \equiv\left(\mu_{i 2} / \mu_{i 1}\right)<V_{2 i} B>/<B^{2}
$$


Here $B, B_{p}$, and $B_{T}$ are the total, poloidal, and toroidal magnetic fields and $\mu_{i 1,2}$ are the neoclassical parallel ion viscosity coefficients whose dependence on the collisionality parameter $v_{*_{j}}$ is shown in Fig. $2 . \quad v_{*_{j}}$ is defined as the ratio of effective collision frequency to bounce frequency, i.e.,

$$
v_{\star_{i}}=\left(1+n_{z} z^{2} / n_{i}\right) R_{q}(r / R)^{-3 / 2} / \tau_{i j} \alpha_{i}
$$

with

and

$$
\tau_{i i}=(3 / 16 \sqrt{2 \pi}) m_{i} \alpha_{i}^{3} / n_{i} e_{i}^{4} \text { en } \Lambda
$$

$$
\alpha_{i}=\sqrt{2 T_{i} / m_{i}}
$$

is the thermal ion speed. $n_{z}$ and $z$ are the impurity density and charge number. .

The angular brackets denote an average over the poloidal magnetic flux surface $\psi=$ constant and the neoclassical diamagnetic velocities $V_{1,2 i}$ are given by

$$
\left.\begin{array}{l}
V_{1 i} B=\left(-F T_{i} / e_{i}\right)\left[\frac{p_{i}^{\prime}(\psi)}{p_{j}}+\frac{e_{j} \phi^{\prime}(\psi)}{T_{i}}\right] \\
v_{2 i} B=\left(-F T_{i} / e_{i}\right)\left[\frac{T_{i}^{\prime}(\psi)}{T_{i}}\right]
\end{array}\right\}
$$

Here $F \equiv R B_{T}$ and $a^{\prime}(\psi) \equiv d a / d \psi=|\nabla a| /|\nabla \psi|=|\nabla a| / R B_{p}$ where "a" stands for the pressure $p_{i}$, the ambipolar potential $\phi$, or the temperature $T_{i}$. While $p_{i}$ and $T_{i}^{\prime}$ are presumably known, $\phi '$ is not, usualiy.

\subsection{Fluid Theory Determination of Ambipolar Potential}

Of all the various possible nonambipolar diffusion processes (such as classical or anomalous perpendicular ion viscosity, magnetic ripple effects, or charge exchange) we have concluded that for the relatively low density small minor radius ORMAK experiment charge exchange is the dominant effect to determine the ambipolar electric field: The same claim has been made for the ATC experiment (KOCH and TANG 1977). 
Quite generally, as shown by HINTON and HAZELTINE (1976), the toroidal angular momentum balance is

$$
\frac{\partial}{\partial t}\left\langle m_{i} n_{i} u_{i} R>+\frac{1}{r} \frac{\partial}{\partial r} r S_{i}=\langle\underline{j} \cdot \nabla \psi\rangle\right.
$$

where $S_{i}$ depends on the perpendicular ion viscosity (which in the absence of neutral injection seems to be classical and therefore negligible) and j. $\nabla \psi$ is the radial electric current due to nonambipolar diffusion. Using Ampere's law (6) becomes

$$
\frac{\partial}{\partial t}\left[\left\langle m_{i} n_{i} u_{i T} R>+\frac{1}{4 \pi}\langle\underline{E} \cdot \nabla \psi\rangle\right]=0\right.
$$

which is the fluid version of conservation of toroidal angular momentum. Observing experimentally that initially (i.e., before reaching the flat current phase) the toroidal momentum is negligible, the integration constant needed to integrate $(6 \mathrm{~b})$ is zero and there results, using again $|\nabla \psi|=\mathrm{RB}_{\mathrm{p}}$

$$
\left.<m_{i} n_{i} u_{i T} R>+\frac{1}{4 \pi}<E_{r} R B_{p}\right\rangle=0
$$

If the toroldal velocity $u_{j T}$ is simply that given in Eqs. (2) and (3) (i.e., containing no charge-exchange effects to leading order), (6c) becomes the determining equation for $E_{r}$ when $u_{j T}$ is taken from (2) and one obtains

$$
-\frac{e_{j} \phi^{\prime}(\psi)}{T_{i}}\left[1+\frac{<\Omega_{p i}^{2}>}{\left\langle\omega_{p i}^{2}>\right.}\right]=\frac{n_{i}^{\prime}}{n_{i}}+\frac{T_{i}^{\prime}}{T_{i}}\left[i+\frac{\mu_{2 i}}{\mu_{1 i}} \frac{\left.\left\langle B_{T}^{2}\right\rangle B^{2}\right\rangle}{\left\langle{ }^{2}\right.}\right]
$$

Here the toroidal plasma dielectric constant $\left\langle\omega_{p i}^{2}\right\rangle /\left\langle\Omega_{p i}^{2}\right\rangle>>1$ so that the coefficient of $\phi^{\prime}$ is practically unity. $\mu_{2 i} / \mu_{1 j}$ varies substantially with $v_{*}$, but not much with the inverse toroidal aspect ratio $r / R$ (see Fig.?). In the banana regime the coefficient of $T_{i}^{1} / T_{i}$ in (7) is -0.17 , in the Pfirsch-Schlüter regime 3.44, thus changing sign in the plateau regime. 
(The same sign change occurs for the poloidal velocity $u_{p i}$ [see Eqs. (1) and (3) ].) When the value (7) is inserted into Eq. (2) for the toroidal velocity $u_{T i}$ one obtains zero to leading order. Thus, to this order, the plasma conserves toroidal angular momentum by adjusting $E_{r}$ until $u_{T i}$ vanishes.

\subsection{Kinetic Theory of Ambipolar Potential}

Consequently, one is forced to determine the higher order (in $\sqrt{r / R}$ and $\left.v_{c x} / \nu_{i j}\right)$ contributions to the toroidal flow velocity $u_{T i}$ from kinetic theory (SIGMAR and CLARKE 1974). Noting that experimentally the effective toroidal flow velocity is solely determined from the wings of the spectral line, i.e., the superthermal ions, the banana-plateau theory will suffice even when the bulk of the ion distribution is strictly in the plateau regime. Then the profile of the $H_{\alpha}$ line of charge-exchange atoms observed tangentially to the toroidal magnetic field can be related to the proton distribution function of parallel velocities $F_{j}\left(v_{\|}\right)=\int 2 \pi v_{\perp} d v_{\perp} f\left(v_{\perp}, v_{\|}\right)$. In the banana-plateau regime, one has $F_{j}=F_{0}+F_{1}$ where $F_{0}$ is Maxwellian (even in $v_{\|}$) and the odd piece in $v_{\|}$is given approximately by

$$
F_{1}=F_{0}\left\{\frac{v_{\| m_{i}}}{T_{i}}\left[\left(\frac{E_{r}}{B_{p}}+u_{g}\right)-\frac{T_{i}}{e_{i} B_{p}}\left(\frac{v_{\|}^{2}}{a_{i}^{2}}-y\right)\left(\frac{\frac{\varepsilon}{2} v_{\star_{i}}+\sqrt{\varepsilon}}{1+v_{\star i}}\right)\right]\right\}
$$

Here,

$$
\alpha_{i}^{2}=\frac{2 T_{i}}{m_{i}}, \varepsilon=\frac{r}{R}, u_{g}=-\frac{T_{i}}{e_{i} B_{p}}\left[\frac{n_{i}^{\prime}(r)}{n_{i}}+\left(y-\frac{3}{2}\right) \frac{T_{i}^{\prime}(r)}{T_{i}}\right]
$$

From HAZELTINE and HINTON (1976), the parameter y (measuring the collisionality of the ions and directly related to Hirshman's $\mu_{i 2} / \mu_{i 1}$ ) is

$$
y=1.31\left(1+1.65 \sqrt{v_{* j}}\right) /\left(1+0.86 \sqrt{v_{* j}}\right),
$$

such that $\left(u_{g}+E_{r} / B_{p}\right)$ and $u_{\| i}$ defined in (2b) and (3) are the same. 
Equation (8) contains the thermal friction due to trapped ion effects and yields the first order in $\sqrt{r / R}$ correction to the parallel flow velocity, i.e.,

$$
u_{\| i}^{(1)}=-1.7 \sqrt{r / R} T_{i}^{\prime}(r) / e_{i} B_{p}
$$

The distortions of $0\left(\nu_{c x} / \nu_{i j}\right)$ of the ion distribution function due to charge-exchange collisions have been neglected since they are not needed to calculate the charge-exchange friction for the ions for which we obtained previously

$$
R_{\| C x}^{i}=-(8 / 3 \sqrt{\pi}) v_{C x}^{0} m_{i} n_{i}\left[u_{\| i}-2.44 \hat{r} / R T_{i}^{\prime}(r) / e_{i} B_{p}\right]
$$

where $u_{\| i}$ is given in (2b).

The electrons do not experience any charge-exchange friction and using the neoclassical flux-friction relation the radial electric current $j_{r}$ becomes

$$
j_{r}=-R_{\| c x}^{j} / B_{\theta}
$$

with $R_{\| c x}^{i}$ given by (12). For times $t>v_{c x}^{-1}$ the asymptotic ambipolarity condition $\langle j \cdot \nabla \psi\rangle=0$ then yields $R_{\| c x}^{i}=0$, from which there results the first-order value for the ambipolar electric field $E_{r}^{(1)}$ determined explicitly. by the charge-exchange dynamics

$$
E_{p}^{1} / B_{p}=2.44 \sqrt{r / R} T_{i}^{\prime}(r) / e_{i} B_{p}+0\left(\nu_{i x} / \nu_{i j}\right)
$$

as given before. As we showed in (7) the zeroth order electric field was determined by

$$
E_{r}^{0} / B_{p}+u_{g}=0
$$

When $\dot{E}_{r}^{0}+E_{r}^{l}$ is substituted into $E q .(8)$ one recovers the final result for the parallel ion distribution function $F_{1}$ (SIGMAR et al., 1974). Here we emphasize an important point, however. The resultant bulk flow velocity of the warm ions becomes 


$$
u_{\| i}=\frac{1}{n_{i}} \int d^{3} v v_{\|} F_{1}=0.73 \sqrt{r} \bar{r} \bar{R} T_{i}^{\prime} / e_{i} B_{p}
$$

with the dominating contributions coming from the bulk $\left(v_{\|} / \alpha_{i} \leq 1\right)$ of the distribution function (not observable because cold neutrals overwhelm the center of the spectral line). Equation (14a) has the opposite sign of the "effective" flow velocity of the superthermal ions (observed in the wings of the spectral line where $\left.v_{\|}^{2} / \alpha_{i}^{2}>1\right)$ which can be gleaned from the last term in Eq. (8) to scale as

$$
u_{\| i}^{e f f} \sim-\sqrt{r / R} T_{i}^{\prime}(r) / e_{i} B_{p}
$$

The observed toroidal "rotation" is in the direction of (14b) (turning around when the plasma current is reversed), has the same order of magnitude as (14b), and scales with plasma parameters as Eq. (14b).

For completeness we mention that the effects of the induced tokamak field, $E_{\phi}$, on the ion drift velocity is an entirely negligible contribution.

\section{LINE PROFILE UNFOLDING TECHNIQUE}

A spectral line profile may be unfolded by fitting it to the sum of two (or more) Gaussians of different intensity, width, and mean displacement. This was the analysis used originaliy. A line profile of $H_{\alpha}$ radiation was assumed to be the sum, $I(\Delta \lambda)$, of two principal components: an unshifted, bright but narrow Gaussian distribution function due to cold plasma, and a shifted, dimmer, but broad distribution function radiated by the hot charge-exchanged neutral population.

$$
I(\Delta \lambda)=\frac{{ }^{\text {cold }}}{\pi^{1 / 2} \Delta \lambda_{D_{\text {cold }}}} \exp \left[-\left(\frac{\Delta \lambda}{\Delta \lambda_{D}}\right)_{\text {cold }}^{2}\right]+\frac{I_{\text {hot }}}{\pi^{1 / 2} \Delta \lambda_{D_{\text {hot }}}} \exp \left[-\left(\frac{\Delta \lambda+\Delta \lambda_{0}}{\Delta \lambda}\right)^{2} D_{\text {hot }}\right]
$$


where the Doppler width, is $\Delta \lambda_{D} \equiv\left(\frac{v}{c}\right) \lambda$. The unshifted wavelength is $\lambda, \Delta \lambda_{0}$ is the wavelength shift, and $v$ is the velocity. Instrumental broadening of the profile, mainly from the 50-micron wide spectrometer entrance slit, was determined to be less than $20 \mathrm{eV}$ at thermal ion temperature and was not a significant factor in the measurements.

The measured line profile was expanded in two Gaussians by a least squares fit as described in SHAVITT (1963). Although the solution is not unique, a maximum likelihood solution with known bias after GOSSLEE and BOWMAN (1958) can be found and consistent compensations made. At the time of the uriginal observation, measurements were made with a time dependent scanning device. The subsequent analysis was sufficiently crude that the toroidal-drift velocity, ion-temperature relation found from the odd and even components of the measured profile on one hand and the two-Gaussian fit on the other, gave essentially the same value, $2.4 \pm 0.5 \times 10^{4} \mathrm{~cm} \mathrm{sec}^{-1} \mathrm{ev}^{-1}$.

A more direct approach to the toroidal-drift velocity, ion-temperature relation has been adopted. It appears to be operating-parameter dependent, and therefore useful as a shot-to-shot plasma quality indicator. The results are the data given in this paper. To a first approximation, the charge-exchanged neutrals which contribute to a specific level of intensity iil Lhe Doppler broadened wings of the $\mathrm{H}_{\alpha}$-line profile have a toroidal-drift velocity and an effective ion-temperature proportional to the centerline shift and the square of the width, respectively, of the line profile at that level of intensity. Since line profile data is collected and digitized for each shot or selected portions of a shot and analys is is by computer, the velocity-energy relation may be read out between shots if the signalto-noise ratio permits. The possibility of direct observation of beam 
injected protons increases the attractiveness of the technique. Our computer printout contained drift velocity and ion temperature for intensity levels at $2,8,18,32$, and $50 \%$ of maximum as in Fig. 3 , but did not calculate $z_{\text {eff }}$ or plot $d V_{\| j} / d T_{j}$.

\section{MEASUREMENTS}

Several $v_{\| j}, T_{i}$ relations are shown in Figs. 4, 5, and 6 for contrasting plasma parameters. Discharge cleaning with oxygen (Fig. 4) usually produced a higher $z_{\text {eff }}$ and a lower toroidal-drift velocity, ion-temperature gradient, $d v_{\| j} / d T_{i}$, than did discharge cleaning with hydrogen. With maximum ohmic heating current and maximum toroidal magnetic field, $\mathrm{dv}_{\| \mathrm{i}} / \mathrm{dT}_{\mathbf{i}}$ was actually negative for some shots. That is, the plasma core appeared to be drifting more slowly than the edges. Here the $\mathrm{Z}_{\text {eff }}$ was about $30 \%$ lower because hydrogen gas was injected (gas puff) during the shot.

$Z_{\text {eff }}$ as used in this paper is that described by COLCHIN et al. (1976) and is obtained empirically from plasma current and electron density at $45 \mathrm{msec}$ after turn-on. Assuming $Z_{\text {eff }}=C I / n_{e}$, where $I$ is in amperes and $n_{e}$ in $\mathrm{cm}^{-3}$, we chose $C=1.25 \times 10^{9}$. This value for $C$ gives a best fit to the $Z_{\text {eff }}$ obtained from inner plasma resistivity measurements, and should be consistent in its relation to absolute $Z_{\text {eff }}$ for a yiven radius.

The data of Figs. 5 and 6 were taken after discharge cleaning with hydrogen. The lowest $z_{\text {eff }}$ was 2 , and the steepest gradient, $d v_{\| j} / d T_{i}$, was $1.7 \times 10^{4} \mathrm{~cm} \mathrm{sec}^{-1} \mathrm{eV}^{-1}$, as in Fig. 5. These values were obtained with modest toroidal magnetic field and ohmic heating current, maximum coinjection power, and an optimized gas puff.

To get maximum density (Fig. 6) the ohmic heating current, toroidal magnetic field, and coinjection power were maximized. Without the gas 
puff, $z_{\text {eff }}$ increased to 9 . With the gas puff, a density of $4.8 \times 10^{13} \mathrm{~cm}^{-3}$, a $Z_{\text {eff }}$ of 4 , and an increased $\mathrm{dv}_{\| j} / \mathrm{dT}_{j}$ were obtained.

A unique opportunity to study the effects of ripple viscosity and microturbulence on toroidal-drift velocity is afforded by this technique. The spatial distribution of ion temperature, $T_{j}(r)$, obtained from the charge-exchange analyzer data together with the toroidal-drift velocity, ion-temperature relation, $v_{\| j}\left(T_{j}\right)$, gives a spatial distribution of toroidal-drift velocity. A steep gradient at the plasma boundary is apparent in the data of Fig. 7. Similarly, we found that with coinjected neutral beam power levels exceeding those of ohmic heating power, the expected order-of-magnitude increase in toroidal drift velocity did not occur (Fusion Energy Division, ORNL, 1977). Rather $v_{\| j}$ was reduced as $Z_{\text {eff }}$ increased. Only with an optimized gas puff could $v_{\|_{i}}$ and $d v_{\|_{i}} / d T_{i}$ be increased. The toroidal-drift velocity gradient, $d v_{\|} / d T_{i}$, dependence on $Z_{\text {eff }}$ is summarized in Fig. 8. Even with the optimized gas puff it does not exceed the average value of the original no-injection, ORMAK-produced plasma.

\section{CONCLUSIONS}

(1) We found that there was sufficient charge-exchange neutral hydrogen radiation (through the energy range up to ten times thermal) from the ORMAK-produced plasma, to measurably raise the intensity in the wings of the $\mathrm{H}_{\alpha}$-line profile above the noise.

(2) We found drift velocities greater than $10^{7} \mathrm{~cm} \mathrm{sec}^{-1}$ and were able to show a consistent relationship to $Z_{\text {eff }}$, neutral density and, foremost, ion temperature. Further electronic development will be required for $\mathrm{dv}_{\| j} / \mathrm{dT}_{j}$ to be displayed between tokamak shots. 
(3) Although the injected neutral beam could not be seen spectroscopically, its effect on the plasma was reflected in lowered toroidaldrift velocity indicating a higher $Z_{\text {eff }}$. Compensation by a delayed gas puff was sufficient to lower $Z_{\text {eff }}$ and provide maximum $d v_{\| j} / d T_{j}$ for the ohmic heating and toroidal magnetic field used.

(4) The spatial distribution of toroidal velocity from $v_{\| j}\left(T_{j}\right)$ and $T_{i}(r)$ indicated a steep velocity gradient at the plasma boundary due, perhaps, to ripple viscosity. The less than expected toroidal-drift velocity with coinjection may indicate the presence of microturbulence. Further work in these applications is indicated.

\section{ACKNOWLEDGEMENTS}

We wish to express our appreciation for continued encouragement and cooperation by the Plasma Theory Section and the Tokamak Experimental Section. 


\section{REFERENCES}

BELL, M. G. (1977) 8th European Conf. on Controlled Fusion and Plasma Phys., Prague, 1, 11 .

CALLEN, J. E., HOGAN, J. T., and WADDELL, B. V. (1973) 3rd Intl. Symp. on Toroidal Plasma Confinement, Garching, Paper B23.

COLCHIN, R. J. et al. (1976) J. Nucl. Mater. 63, 74.

Fusion Energy Division Annual Report for Period Ending December 31, 1976

(1977) ORNL-5275, Oak Ridge National Laboratory, Oak Ridge, Tennessee.

GUSSLEt, U. G. and BUWMAN, K. U. (unpublished) "Evaluation of Maximum

Likelihood Estimates of Parameters in Mixtures of Normal Distributions,"

ORNL/TM-2110, Oak Ridge National Laboratory, Oak Ridge, Tennessee.

HAZELTINE, R. D. and HINTON, F. L. (1973) Phys. Fluids 16, 1883.

HINTON, F. L. and HAZELTINE, R. D. (1976) Revs. Mod. Phys. 48, 289.

HIRSHMAN, S. P. "Moment Equation Approach to Neoclassical Transport Theory," PPPL-1378, Phys. Fluids 21, in press.

KOCH, R. A. and TANG, W. M., PPPL-1381 (1977) Princeton Plasma Physics Lab.

ROSENBLUTH, M. N., RUTHERFORD, P. H., TAYLOR, J. B., FRIEMAN, E. A., and

KOVRIZHNIK, L. M. (1971) Plasma Physics and Controlled Nucl. Fus.

Research (IAEA, Vienna) 1, 495.

SHĀVITT, I. (1963) Methods of Computational Physics, Academic Press.

SIGMAR, D. J., CLARKE, J. F., NEIDIGH, R. V., and VANDER SLUIS, K. L.

(1974) Phys. Rev. Lett. 33, 1376.

SIGMAR, D. J. and CLARKE, J. F. (unpublished) "Effect of Charge-Exchange on Neoclassical Transport," ORNL/TM-4606, Oak Ridge National Laboratory:

Oak Ridge, Tennessee.

STRINGER, T. E. (1970) Phys. Fluids 13, 810.

TSANG, K. T. and FRIEMAN, E. A. (1976) Phys. Fluids 19, 747.

TSANG, K. T. private communication (1977).

ZAVOISKY, E. K. and RUDAKOV, L. I. (1967) Soviet Atomic Energy 23, 1171. 


\section{FIGURE CAPTIONS}

Fig. 1. Data collection system schematized. The insert depicts the projection of the ORMAK-produced plasma by the wide angle lens system. The spectrometer was positioned so that its entrance slit selected the desired portion of the projection.

Fig. 2. The dependence of the ratio of parallel ion-viscosity coefficients on the collisionality parameter $v_{*_{j}}$. In the banana regime $v_{*_{j}}<1$, plateau $1<v_{\star_{j}}<\delta^{-3 / 2}$, and Pfirsch-Schlüter $v_{\star}>\delta^{-3 / 2}$.

Fig. 3. Spectral-line profile of $H_{\alpha}(6563 \AA)$. The line width and displacement of its center of gravity are measured at intensity levels of $2,8,18,32$, and $50 \%$ of maximum and are related to ion temperature and toroidal-drift velocity, respectively.

Fig. 4. $\quad v_{\| j i} / T_{i}$ after $0_{2}$ discharge cleaning. Characteristically, after discharge cleaning with oxygen, analys is of the $H_{\alpha}$ profile. indicated a low temperature and shallow drift velocity gradient. The "hollow" spatial profile was the result of maximum ohmic heating power and no injection. The slowest velocities may be in error by a factor of two. However, the relative velocity error between curves is much less. See rigs. 5 and 6 and text.

Fig. 5. $\quad v_{\| j} / T_{j}$ after $H_{2}$ discharge cleaning. The effects of neutral gas injection can readily be seen in the "peaking" of toroidal velocity. The error bars indicate scatter in the multishot data from which the line profile is obtained. Even though straight lines have been drawn through the data points, there is usually a decrease in $d v_{\| l} / d T_{j}$ at the higher temperature, as indicated by the dashed curve. 
Fig. 6. $v_{\| j} / T_{i}$ for maximum power input. Maximum ohmic and injected power, but without gas injection, results in high $Z_{\text {eff }}$ and low toroidal velocity. A marked increase in signal level and $d v_{\| j} / d T_{j}$ accompanies gas puffing through the fast gas valve. The dashed lines indicate the maximum error in the velocity measurement. It is a common positioning error, due to difficulty in measuring the upstream and downstream viewing angles accurately.

Fig. 7. $v_{\| j}(r)$. from $T_{j}(r)$ and $v_{j}\left(T_{i}\right)$. Error bars indicate scatter in drift velocity measureinient. $T_{j}(r)$ is a best fit of dàta to $\mathrm{T}_{i}=513\left[1-\left(\frac{r}{\mathrm{a}}\right)^{2}\right]^{1.16}$.

Fig. 8. Gas puff optimization. Neutral beam injection and maximum ohmic heating raise the impurity level $\left(Z_{\text {eff }}\right)$. The optimized hydrogen gas puff raises the density and also the toroidal drift velocity, indicative of a lower $z_{\text {eff }}$. The effect is noticeably less if the liner has been discharge cleaned with oxygen. The dashed horizontal line was the average $\mathrm{dv}_{\| j} / \mathrm{dT}_{j}$ given in the original publication. 
ORNL - DWG 77-6411

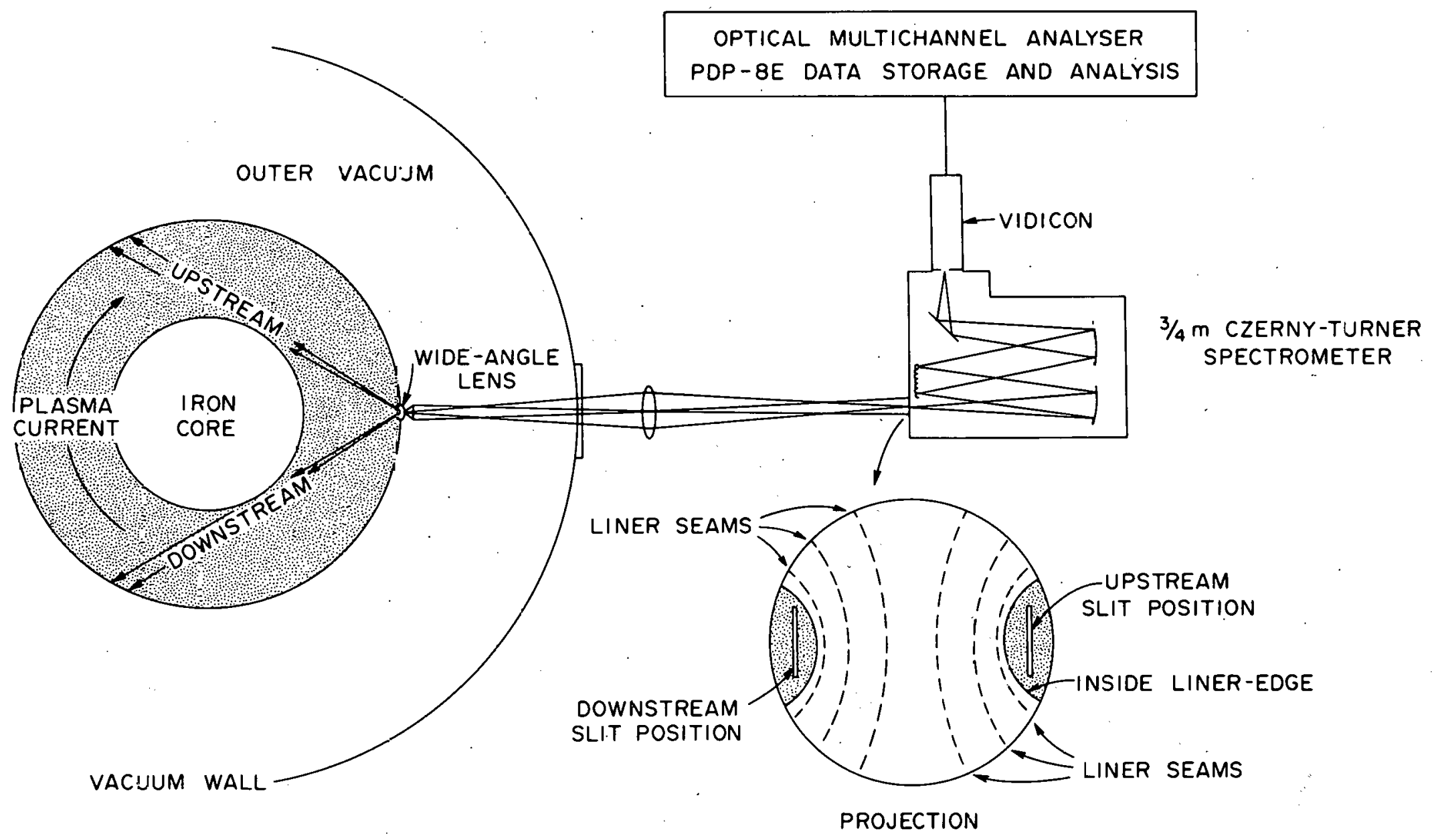

Fig. 1. 


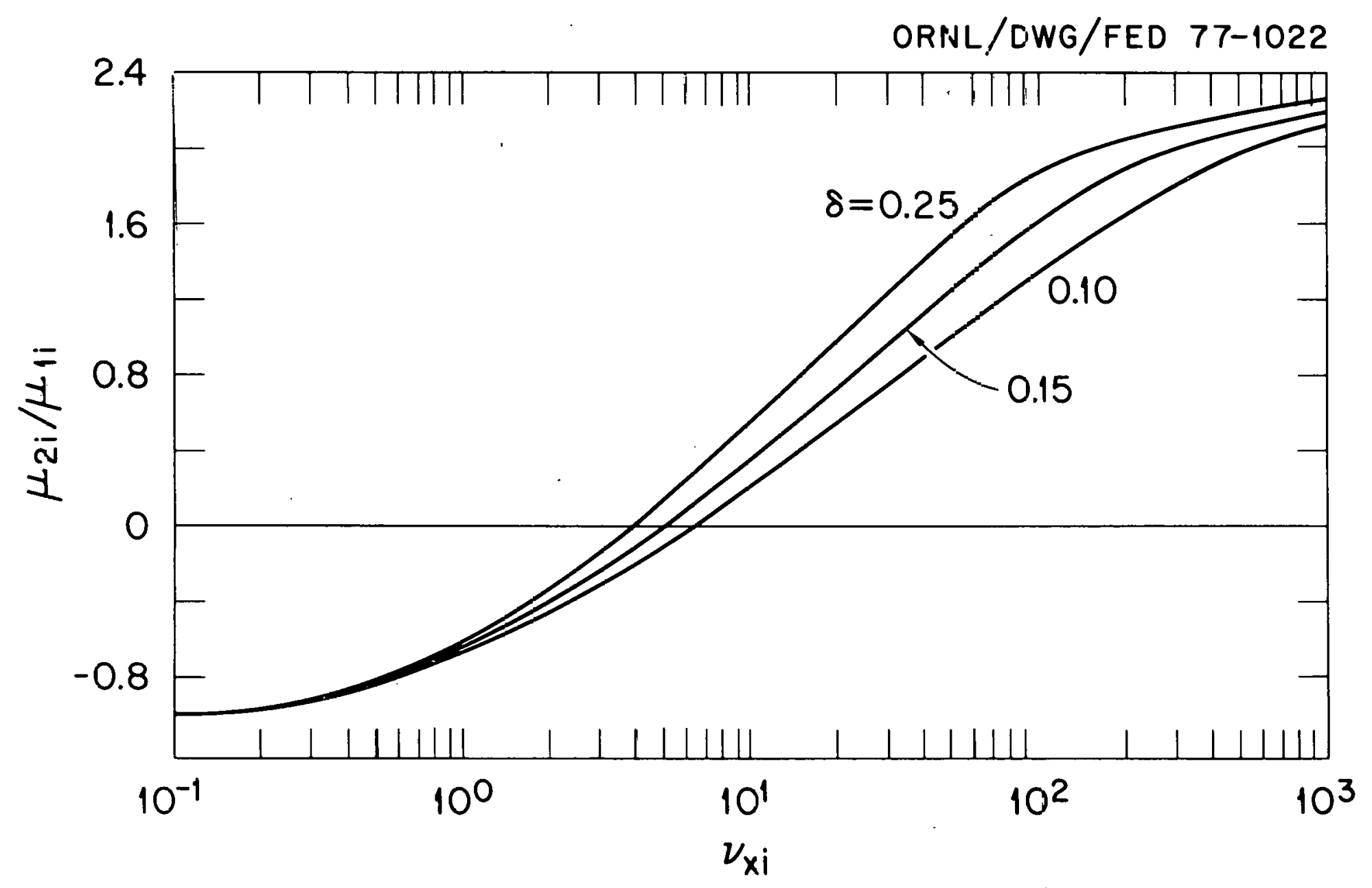

Fig. 2 . 


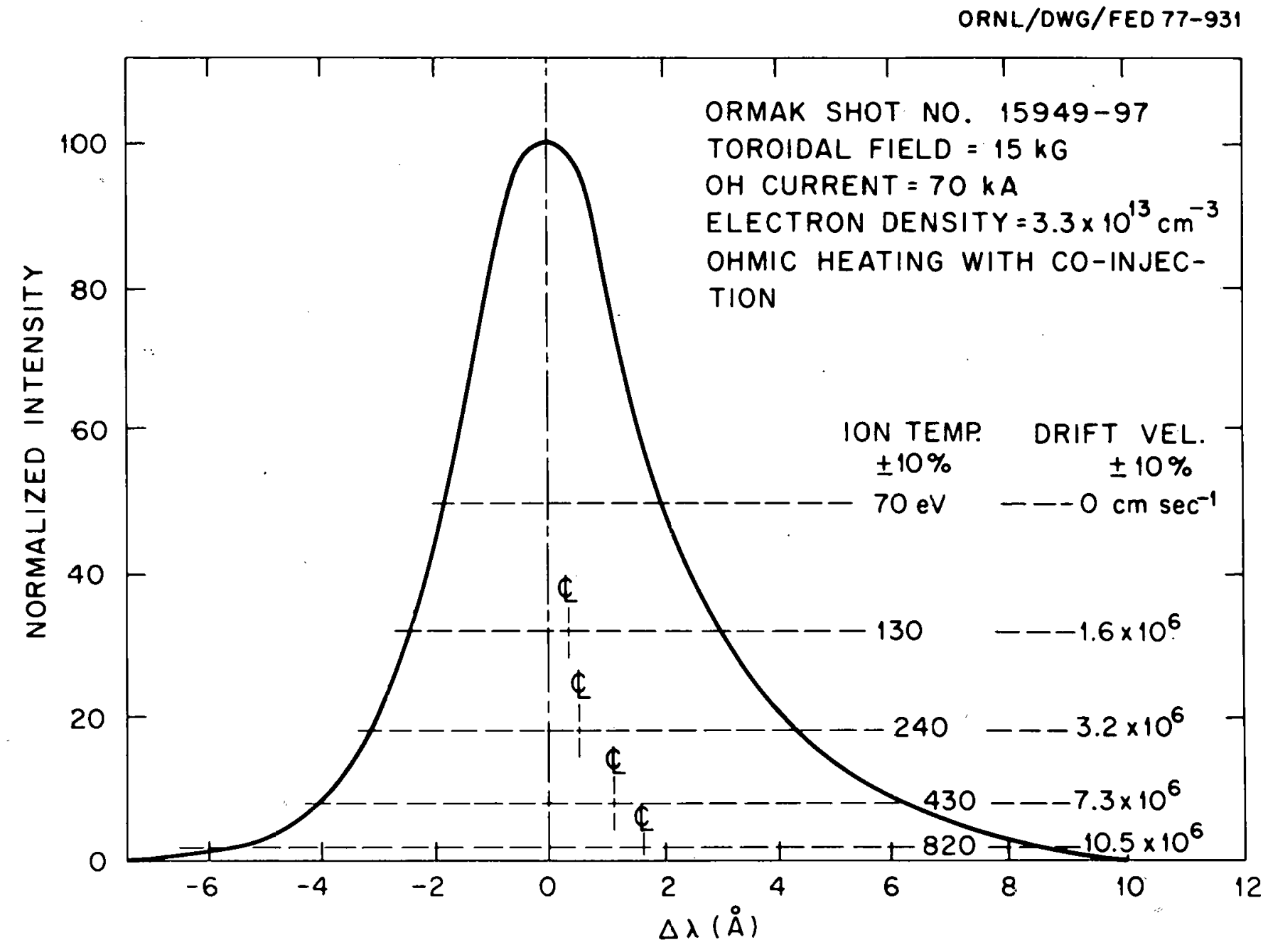

Fig. 3 . 


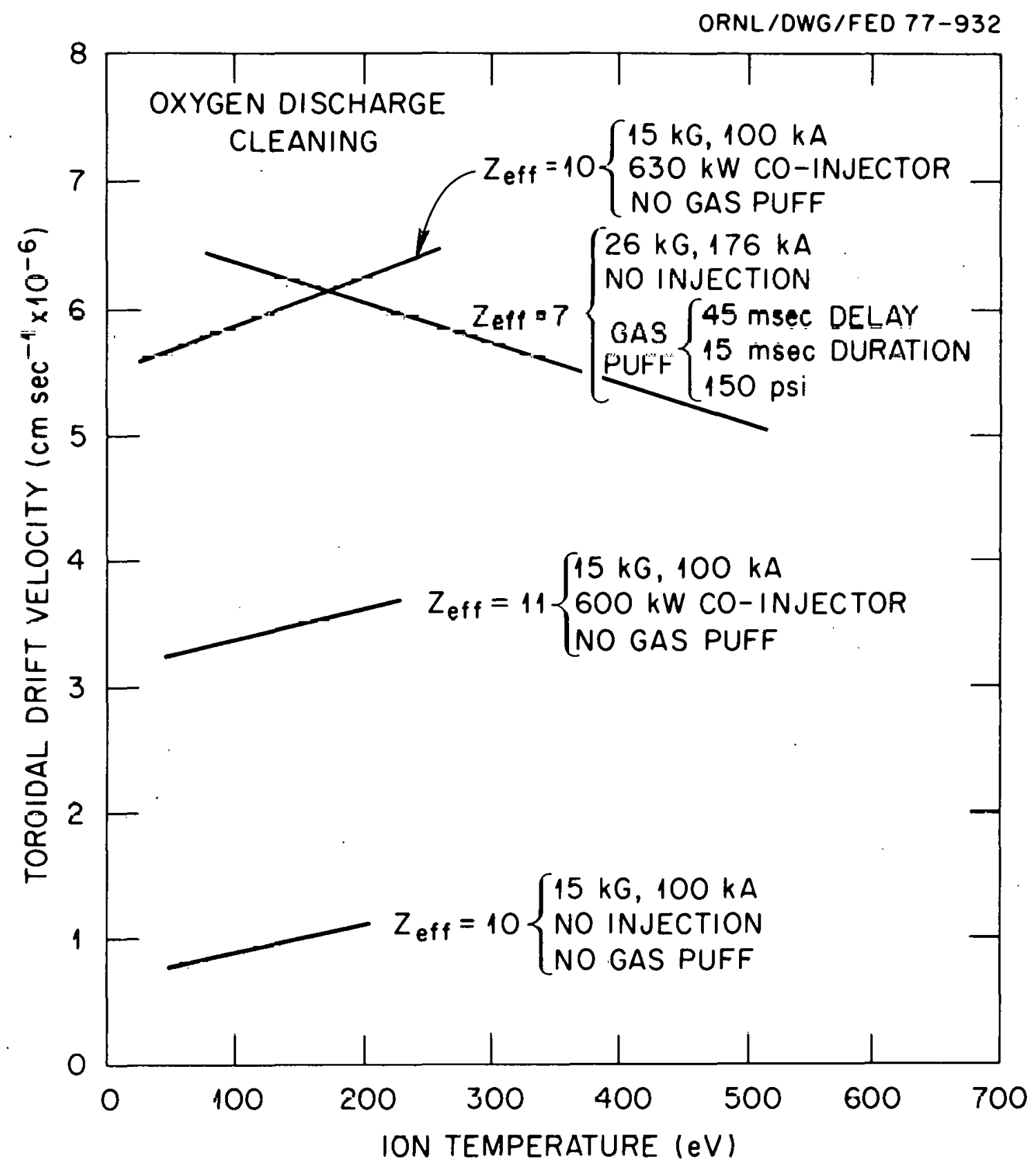

Fig. 4. 


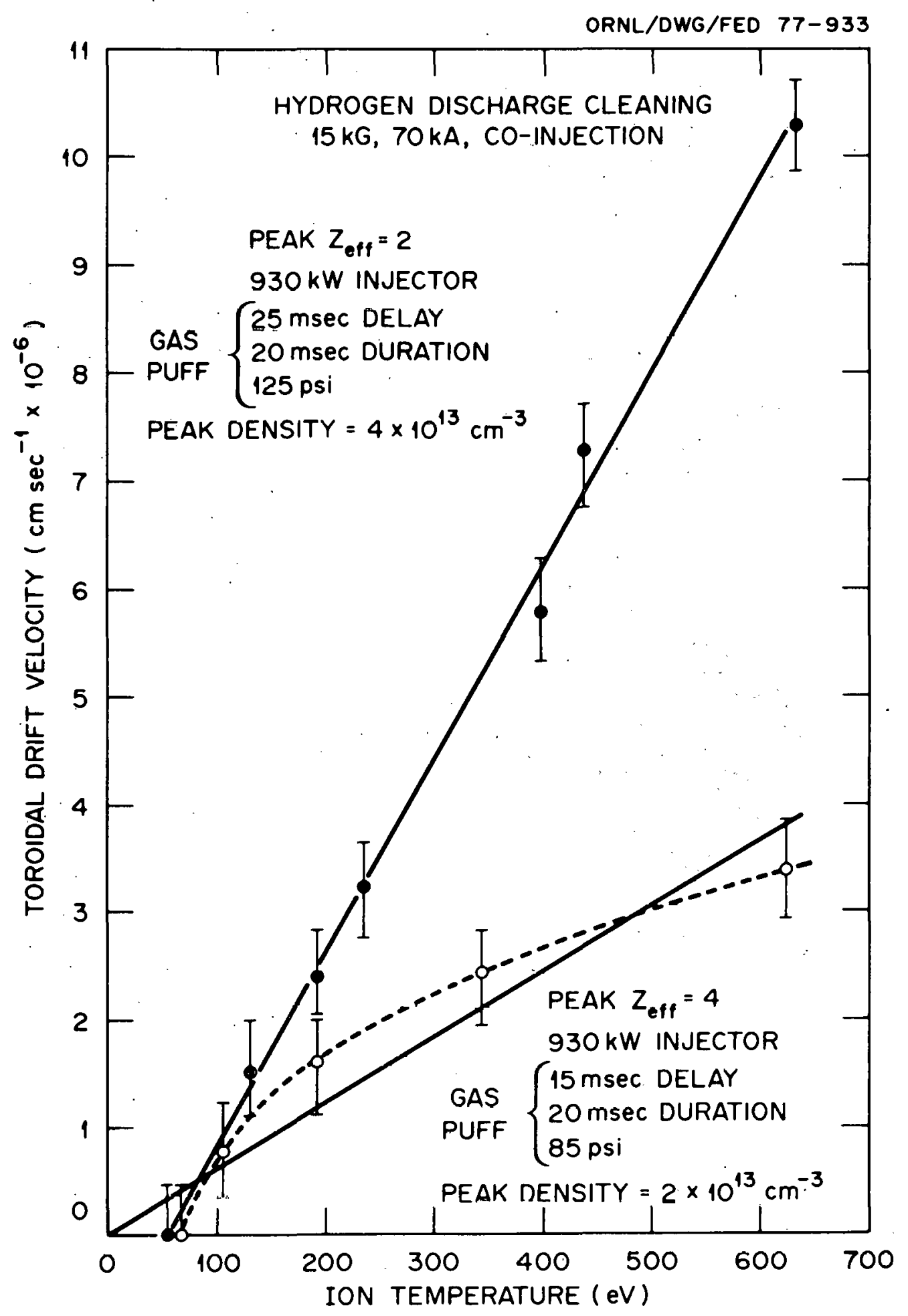

Fig. 5 . 


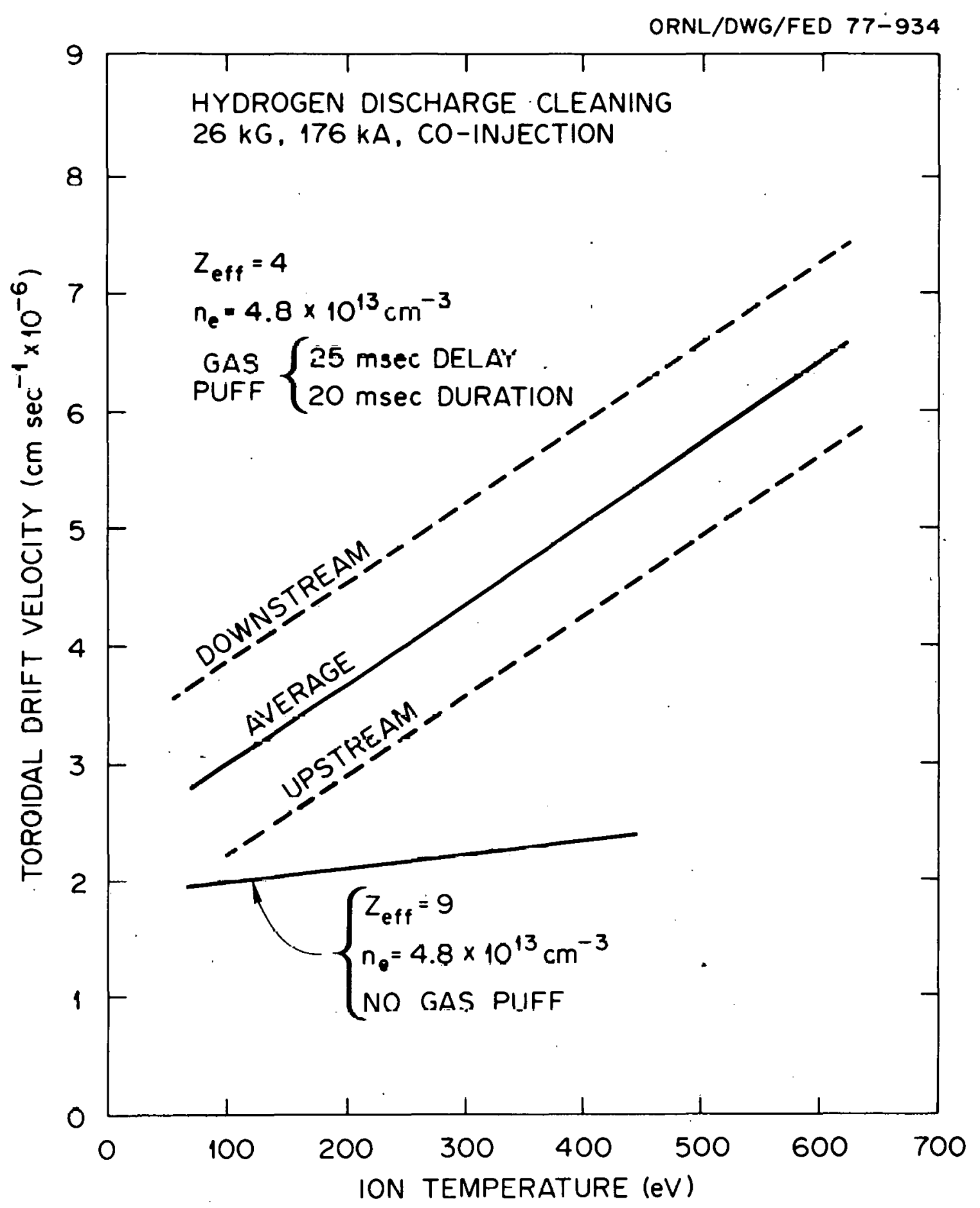

Fig. 6. 


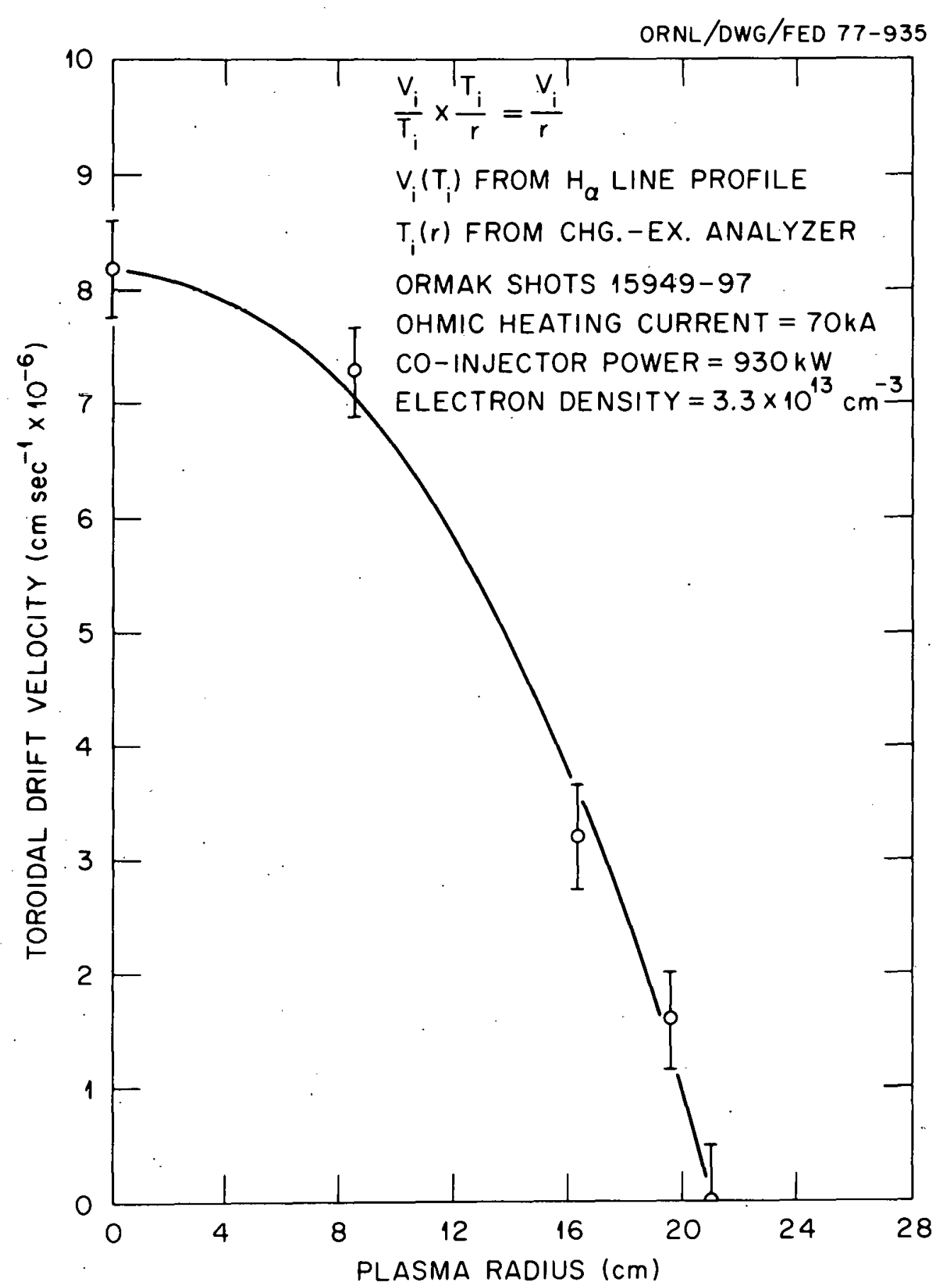

Fig. 7. 


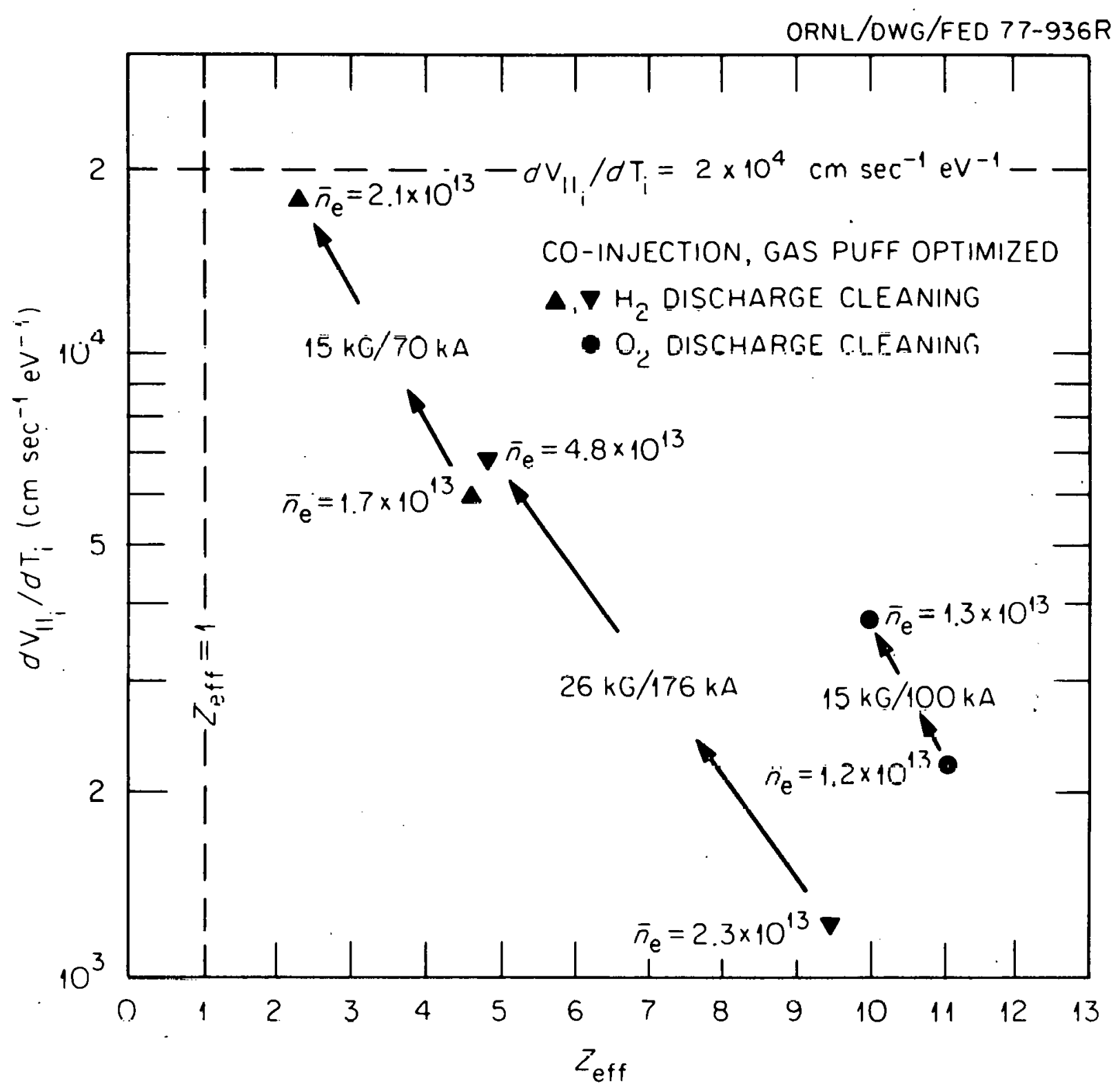

Fig. 8. 
ORNL/TM-6198

\section{INTERNAL DISTRIBUTION}

1. C. F. Barnett

2. L. A. Berry

3. C. E. Bush

4. J. D. Callen

5. R. J. Colchin

6. R. A. Dandl

7. R. A. Dory

8. J. L. Dunlap

9. P. H. Edmonds

10. A. C. England

11. H. H. Haselton

12. C. L. Hedrick

13. J. T. Hogan

14. K. W. Hill

15. R. C. Isler

16. T. C. Jernigan

17. G. G. Kelley

18. H. E. Ketterer

19. P. W. King

20. J. F. Lyon

21. H. C. McCurdy

22. D. H. McNeill

23. J. T. Mihalczo

24. R. Miskell
25. 0. B. Morgan

26. M. Murakami

27-36. R. V. Neidigh

37. G. H. Neilson

38. V. K. Pare

39. Y-K. M. Peng

40. J. A. Rome

41. M. W. Rosenthal

42. J. Sheffield

43-52. D. J. Sigman

53. J. E. Simpkins

54. W. L. Stirling

55. D: W. Swain

56. K. Tsang

57. J. B. Wilgen

58. W. R. Wing

59-60. Laboratory Records

61. Laboratory Records, ORNL-RC

62. Document Reference Section

63-64. Central Research Library

65. Fusion Energy Division Library

66. Fusion Energy Division

Communications Center.

67. ORNL Patent Office

\section{EXTERNAL DISTRIBUTION}

68. M. G. Be11, Institute of Advanced Studies, Canberra, A.C.T. 2600, Australia

69. J. F. Clarke, Associate Director, Office of Fusion Energy, Mai 1 Code G-234, Department of Energy, Washington, DC 20545

70. N. A. Davies, Confinement Systems, Officc of Fusion Energy, Mail Code G-234, Deparment of Energy, Washington, DC 20545

71. S. 0. Dean, Confinement Systems, Office of Fusion Energy, Mail Code G-234, Department of Energy, Washington, DC 20545

72. H. K. Forsen, Exxon Nuclear Company, 777 106th Avenue, N.E., Bellevue, WA 98009

73. H. P. Furth, Plasma Physics Laboratory, Princeton University, P.0. Box 451, Princeton, NJ 08540

74. A. Gibson, Culham Laboratory, Abingdon, Oxfordshire, England

75. R. W. Gould, Professor of Electrical Engincering and Fhysics, Building 116-81, California Institute of Technology, Pasadena, CA 91125

76. R. L. Hirsch, Exxon Research and Engineering Company, P.0. Box 101, Florham Park, NJ 07932 
77-84. T. S. Hsu, Confinement Systems, Office of Fusion Energy, Mail Code G-234, Department of Energy, Washington, DC 20545

85. D. L. Jassby, Plasma Physics Laboratory, Princeton University, P.0. Box 451, Princeton, NJ 08540

86. E. E. Kintner, Director, Office of Fusion Energy, Mail Code G-234, Department of Energy, Washington, DC 20545

87. D. M. Meade, Plasma Physics Laboratory, Princeton University, P.0. Box 451, Princeton, NJ 08540

88. D. Overski, Francis Bitter National Magnet Laboratory, Massachusetts Institute of Technology, 170 Albany Street, Cambridge, MA 02139

89. D. Pfirsch, Max-Planck Institut fur Physik und Astrophysik, 8 Munich 23, Fohringer Ring 6, Germany

90. P. J: Reardon, Plasma Physics Laboratory, Princeton University, P.0. Box 451, Princeton, NJ 08540

91. D. J. Rose, Department of Nuclear Engineering, Massachusetts Institutie of Technoloqy, Cambridge, MA 02139

92. P. H. Rutherford, Plasma Physics Laboratory, Princetun University, P.0. Box 451 , Princeton, NJ 08540

93. A. M. Sleeper, Confinement Systems, Office of Fusion Energy, Mail Code G-234, Department of Energy, Washington, DC 20545

94. P. Stott, Cuiham Laboratory, Abingdon, Oxfordshire, England

95. J. M. Williams, Assistant Director for Development and Technology, Office of Fusion Energy, Mail Code G-234, Department of Energy, Washington, DC 20545

96. J.W. Willis, Confinement Systems, Office of Fusion Energy, Mai7 Code G-234, Department of Energy, Washington, DC 20545

97. H. H. Woodson, Chairman, Department of Electrical Engineering, The University of Texas at Austin, Austin, TX 78712

98. Director, Research and Technical Support Division, DOE-ORO, P.U. Box $t$, Uak R1dye, TN 37830

99-125. Technical Information Center, P.0. Box E, Oak Ridge, TN 37830 